\title{
Stock Recommendations in Swedish Printed Media: Leading or Misleading?*
}

\author{
Erik R. Lidén ${ }^{\dagger}$
}

19th November 2004

*The author gratefully acknowledges comments on this paper received from participants in the 2003 FMA Doctoral Tutorial in Dublin, Ireland. The following also deserves thanks for helpful comments: Brad Barber, Hemang Desai, Henrik Röhs, Boo Sjöö, Clas Wihlborg, and an anonymous referee for helpful comments. I am thankful for financial support received from Bankforskningsinstitutet. The usual disclaimer applies.

${ }^{\dagger}$ Göteborg University, School of Economics and Commercial Law, Dept. of Economics, Box 640, 40530 Göteborg, Sweden. E-mail: Erik.Liden@economics.gu.se Telephone: +46317731330. 


\begin{abstract}
This paper analyzes the initiated and changed recommendations published in six well-known Swedish newspapers and business magazines for the period 1996-2000 using a buy-and-hold abnormal returns (BHARs) approach. The results distinguish between recommendations from analysts and journalists. Buy recommendations were misleading investors, whereas sell recommendations were leading them, overall yielding returns in line with the market. This asymmetry is due to positive information from the management of the company being more intricate to interpret than negative. The information provided by management is generally positively biased, both for good and bad information. This phenomenon holds for recommendations from both analysts and journalists. Following buy- and sell recommendations from analysts yielded BHARs in line with the BHARs from following journalist recommendations, which in turn give rise to returns in line with the market.
\end{abstract}

Key words: Stock recommendations, EMH, Printed media, Initiations, Information asymmetry.

JEL Classifications: G10, G14, G20. 


\section{Introduction}

Buy- and sell recommendations by financial analysts and journalists are regularly published in newspapers and business magazines, and many investors rely upon such investment advice. Recent scandals in the financial industry have unfortunately put their trust in doubt. It is therefore of primary interest to evaluate whether such advice has any real long-term value. Many of the recommendations that surfaces in the printed media are nothing else than reiterations of previous recommendations, often of the same journalist or analyst published in the same source. This paper studies the postpublication performance of new buy- and sell recommendations published in Swedish newspapers and business magazines during the period 1996-2000, an approach enabling us to judge on the stock-picking skills of those behind the recommendations.

It has been suggested that stock recommendations in newspapers and business magazines would be profitable for investors to follow. ${ }^{1}$ Other studies claim the opposite, concluding that markets are (at least) semi-strong efficient. ${ }^{2}$ Prior studies have nevertheless failed to establish whether or not abnormal profits could be made based on this kind of investment advice, and why buy recommendations have no investment value while sell recommendations have. We try to bring clarity to the issue by answering whether stock recommendations in Swedish printed media are leading investors or if they are misleading them. Unfortunately, there are few long-term performance studies on published stock recommendations in newspapers and business magazines, and previous long-term performance research has mainly addressed stock recommendations in other sources. ${ }^{3}$

The competition among newspapers and business magazines is fierce to sell as many single copies as possible. More than 80 percent of the population in Sweden were stockholders in the year of 2000, so publishing stock recommendations was a way for them to attract additional subscribers. ${ }^{4}$ Pub-

\footnotetext{
${ }^{1}$ See Desai et al. (2000).

${ }^{2}$ See Liang (1999), Mathur and Waheed (1995), and Muradoğlu and Yazici (2002).

${ }^{3}$ In Womack (1996) it was found that the post-publication drift for buy recommendations from U.S. brokerage houses was modest and short-lived but for sell recommendations it was large and extended for six months; in Bjerring et al. (1983) it was shown that investors following the advice from a Canadian brokerage house would have earned significant abnormal returns; in Ferreira and Smith (2003) the recommendations presented on Louis Rukeyser's Wall \$treet Week TV-show were shown to generate significant holding-period returns a year after the announcement, and in Barber et al. (2001) an investor who followed the most favorable consensus recommendations was shown to earn an annual return of four percent.

${ }^{4}$ From a survey by TEMO in 2000. In 1995 it was 53 percent, thus a 51-percent increase.
} 
lishing stock recommendations is nevertheless a sensitive task for newspapers and business magazines since they may receive future critique from investors who lost money from following them. Some would even go as far as arguing that newspapers and business magazines bear a part of the responsibility for the "bubble" that occurred on stock markets during the latter half of the nineties. With ever-increasing stock prices, some analysts and journalists kept on recommending so-called dot-com firms, and as we know, prices eventually became unrealistically high for a majority of these stocks.

Most studies in this area have been conducted on the considerably larger U.S. stock markets. The Swedish stock market should be appealing to researchers since it is much smaller with a more limited number of actors, and because its concentration of telecommunication- and internet companies. ${ }^{5}$ About a third of the total market share was owned by foreign owners during the studied period. Compared with the fraction of U.S. equities held by foreign investors which was 12 percent in June 2002, foreign ownership is about three times as common on the Swedish stock markets. ${ }^{6}$

Short-term abnormal returns from stock recommendations published in Swedish newspapers and business magazines were previously studied in Lidén (2003). Sell recommendations were found to generate a statistically significant negative cumulative abnormal return for the 20 post-publication days which essentially implies that money could be made from following these recommendations; recommendations from journalists had a larger impact, on and around the announcement day, than those from analysts; the most positive buy recommendations were published during weekdays, whereas the most negative sell recommendations were published during weekends.

The results of this study show that stock markets react to initiated or changed recommendations at and around the publication day, and that the impact during these few days was much higher to journalist recommendations than it was for analyst recommendations just as was found in Lidén (2003). If an investor was to follow the investment advice (both buy- and sell recommendations) published by either analysts or journalists, he/she would earn returns in line with the market over the 24 post-publication months. One has to keep in mind that this strategy involves shorting the stocks that were sell-recommended, an action which is sometimes not feasible. If one were

\footnotetext{
${ }^{5}$ See Karmin (2000) where the Swedish stock market was pointed out as a market with many investment opportunities in telecommunication- and internet companies. Because of its high concentration of these stocks, it drew much attention during 1999 and 2000 from domestic as well as foreign investors.

${ }^{6}$ Figure B of the Appendix shows how market share is divided between Swedish- and foreign ownership during the period 1982 and 2002. For the U.S. numbers, see Bertaut and Griever (2004).
} 
to follow the sell recommendations alone, an investor would earn significant BHARs. An investor adopting the strategy to short all socks being recommended irrespective of its origin and type, would earn a 24-month BHAR of about 10 percent. Finally, buy recommendations were misleading investors whereas sell recommendations were leading them. This asymmetry is due to the complexity in interpreting the positive information from the company management leading to buy recommendations. Indeed, management seems to be overoptimistic both when they present positive and negative information. The task for analysts and journalists is to translate this positively biased information into more realistic estimations, free from overoptimism.

Section 2 describes the data, while Section 3 explains used method and analyzed hypotheses. The results are presented in Section 4 . Section 5 summarizes and draws conclusions.

\section{Sample Selection and Descriptive Statistics}

The data consists of stock recommendations in Swedish printed media during the period 1996-2000. The recommendations from the following six newspapers and business magazines were considered: Affärsvärlden (AFV); Aftonbladet (AB); Finanstidningen (FTi); Göteborgsposten (GP); Privata Affärer (PA); and Veckans Affärer (VA). ${ }^{7}$ Circulation figures are presented in Table A of the Appendix. The columns containing the recommendations were allocated using the online articles databases Mediearkivet and Affärsdata.

The total sample in the 1996-2000 period consists of 1775 recommendations. Reiterations of previous recommendations occur frequently, though some newspapers and business magazines are over-represented. From these, 1234 (69 percent) are reiterated recommendations. We assume that considered newspapers and business magazines make up the Swedish printed media when it comes to publishing stock recommendations. When a stock receives a buy recommendation in one newspaper or business magazine, if it then receives a buy in another printed source, before it receives a sell, it is deleted from the final sample irrespective in what newspaper or business magazine it is published. By using this approach, we hope to include only the new buyand sell recommendations in the Swedish printed media. ${ }^{8}$ Allowing only initiations or changes from a buy- to a sell recommendation, or vice versa, the sample totals to 541 recommendations. Finally, we allow this procedure to be used from 1995, although we are interested in the period beginning at 1996, just to ensure that we are left with initiated recommendations or

\footnotetext{
${ }^{7}$ For a description of the respective newspaper or business magazine, see Lidén (2003).

${ }^{8}$ This approach have also been used in Womack (1996), among others.
} 
changes from a previous view in that stock. This practically means that a stock which is buy-recommended in 1995 and then receives a buy recommendation in 1996 (without a sell recommendation in between), is deleted from the final sample. The number of buy recommendations are 317 (59 percent of initiations and changes) and sell recommendations 224; thus a buy-to-sell ratio of 3:2. A recommendation could be given either by an analyst or a journalist.

Table 1 describes the distribution of added-to-buy and added-to-sell recommendations among the six newspapers and business magazines, and also partitioned into those originating from analysts and journalists.

Table 1: Distribution of initiated and chnaged recommendations over newspapers and business magazines during the period 1996-2000 in Swedish printed media.

Newspaper/Business magazine

\begin{tabular}{lrrrrrrrrr} 
Type & AFV & AB & FTi & GP & VA & PA & Total & Analysts & Journalists \\
\hline Buy & 40 & 39 & 46 & 54 & 74 & 64 & 317 & 99 & 218 \\
Sell & 42 & 103 & 33 & - & 7 & 39 & 224 & 35 & 189 \\
All & 82 & 142 & 79 & 54 & 81 & 103 & 541 & 134 & 407
\end{tabular}

\subsection{Analysts and Journalists}

We define an analyst as a person employed by a bank, a brokerage firm, or similar; and a journalist as a person employed by a newspaper or business magazine to write articles. Usually, an analyst is asked directly by the newspaper or business magazine to publish articles containing recommendations in that newspaper or business magazine. The bank or brokerage firm the analyst represents, have private clients which they on a regular basis give investment advice. Clients pay with commission for this advice. The "private" information the analyst may possess will thus be passed on to clients to profit from before disseminating it for free to the public. Certainly, the recommendations published in the newspaper and business magazines from analysts will be second-hand information. Journalists, on the other hand, often publish recommendations as a routine in their daily work. They may support their recommendations on: previous reports from the company; an analysis from a bank; or they can be a result of more "investigative" work. There are two major differences between analysts and journalists to consider 
when we analyze investment advice published from these groups.

First, the available information differs. A journalist is typically working on articles for a very limited period of time and does not have the access to all detailed information that the analyst would have. Furthermore, analysts are supported by a whole chain of staff specialized in processing detailed information and presenting it in a standardized manner. This is clearly an informational advantage for analysts over journalists. Also CEOs, CFOs, and other senior officers at a company, may be more willing to meet with analysts to discuss the company than meeting with journalists, since analysts can attract (more) potential investors. This way, analysts can gather information which journalists generally will not.

Second, there is a clear difference in the set of incentives. There are typically no incentives for journalists to give either a favorable or an unfavorable recommendation. The reason is that all newspapers and business magazines demand a non-trade policy from journalists including the family, in stocks that they cover. ${ }^{9}$ The analyst, on the other hand, has several incentives to give a certain type of recommendation (other than personal). Newspapers and business magazines only require of analysts to follow the rules imposed on them by their employer. The bank or brokerage firm the analyst represents may be involved in, or hope to win, a corporate finance deal with the company at hand. Also, the buy-side clients of the bank, or the bank itself, may have taken positions or intend to take positions that would "need" a recommendation along the way. Finally, the bank can give a recommendation in order to increase income from increased transaction volume.

All these situations may tempt analysts to give a certain type of recommendation. The above differences in job description between analysts and journalists consequently motivates us to distinguish between them in the analysis of the results.

\section{$2.2 \quad$ Descriptive Statistics}

Table 2 displays summary statistics for the recommended firms by analysts and journalists including mean, median, and standard deviation of market capitalization (Panel A), as well as sector-index classification (Panel B).

The mean market capitalization of all firms in the sample was Swedish krona (SEK) 32.2 billion, while the median was SEK 2.7 billion. At the end of year 2000, the mean of all firms listed on Stockholm Stock Exchange (SSE) was SEK 11.6 billion, while the median was SEK 0.9 billion. Rec-

\footnotetext{
${ }^{9}$ For a detailed explanation of how the newspapers and business magazines in this paper monitor and regulate journalist stock trades, see Lidén (2003).
} 
Table 2: Sample statistics. Market capitalization figures are presented in Swedish krona (SEK) billion. Numbers in parentheses indicates percentage of group total.

Panel A: Market capitalization

\begin{tabular}{lrrrrrr} 
& \multicolumn{2}{c}{ Analysts } & \multicolumn{2}{c}{ Journalists } & \multicolumn{2}{c}{ All } \\
& & & & & & \\
& Buy & Sell & Buy & Sell & Buy & Sell \\
& 99 & 35 & 218 & 189 & 317 & 224 \\
\hline Mean & 42.7 & 18.2 & 22.4 & 40.7 & 28.7 & 37.2 \\
Median & 3.2 & 2.9 & 2.1 & 3.3 & 2.3 & 3.2 \\
Standard deviation & 175.0 & 26.2 & 71.0 & 143.0 & 114.0 & 132.0
\end{tabular}

Panel B: Industry distribution

\begin{tabular}{lrrrrrr} 
& \multicolumn{2}{c}{ Analysts } & \multicolumn{2}{c}{ Journalists } & \multicolumn{2}{c}{ All } \\
Industry & Buy & Sell & Buy & Sell & Buy & Sell \\
& 99 & 35 & 218 & 189 & 317 & 224 \\
\hline Energy & $1(1)$ & $1(3)$ & $0(0)$ & $0(0)$ & $1(1)$ & $1(0)$ \\
Materials & $11(11)$ & $3(9)$ & $14(6)$ & $18(10)$ & $25(8)$ & $21(9)$ \\
Industrials & $28(28)$ & $12(34)$ & $65(30)$ & $49(26)$ & $93(29)$ & $61(27)$ \\
Consumer discretionary & $14(14)$ & $6(17)$ & $31(14)$ & $20(11)$ & $45(14)$ & $26(12)$ \\
Consumer staples & $0(0)$ & $0(0)$ & $9(4)$ & $5(3)$ & $9(3)$ & $5(2)$ \\
Health-care & $12(12)$ & $1(3)$ & $14(6)$ & $16(8)$ & $26(8)$ & $17(8)$ \\
Financials & $14(14)$ & $5(14)$ & $31(14)$ & $24(13)$ & $45(14)$ & $29(13)$ \\
Information technology & $18(18)$ & $6(17)$ & $51(18)$ & $54(29)$ & $69(22)$ & $60(27)$ \\
Telecommunication services & $1(1)$ & $0(0)$ & $3(1)$ & $3(2)$ & $4(1)$ & $3(1)$ \\
Utilities & $0(0)$ & $1(3)$ & $0(0)$ & $0(0)$ & $0(0)$ & $1(0)$ \\
& & & & & & \\
\hline \hline
\end{tabular}

ommended firms consequently had a substantially higher market capitalization than the average firm listed at the SSE. Firms sell-recommended by journalists were discernably larger than those sell-recommended by analysts, whereas the opposite was true for buy recommendations, though the difference in that case was not statistically significant. Overall, the industrials sector received most buy recommendations and the information technology sector most sell's (Panel B). The dispersion of recommendations over industry sectors was similar for analysts and journalists.

Figure 1 shows the number of added-to-buy and added-to-sell recommendations per year in the sample, as well as the ratio between the two during that particular year.

The number of new recommendations had a fivefold increase from 1996 to 
Figure 1: Recommendations per year. Grey bars indicate added-to-buy recommendations and the black bars added-to-sell recommendations. The line indicates their ratio.

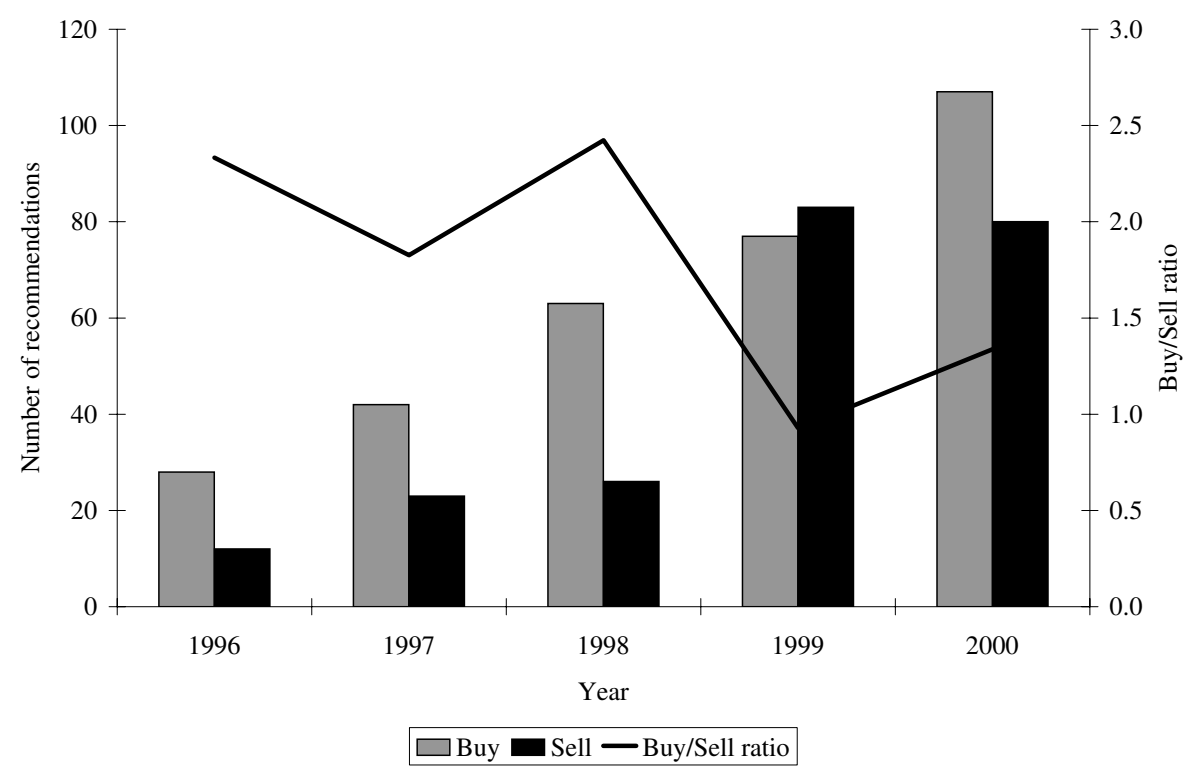

2000. From the figure we can also see that the buy-to-sell ratio of initiations and changes decreased from its highpoint in 1998 of 5:2, to approximately 1:1 in 1999, and 3:2 in 2000. The main reason to the decrease in the ratio is the "overheated" market during 1999 and 2000, which lead to an increased sceptism to buy stocks at the time. In 1999, added-to-sell recommendations actually outnumbered added-to-buy recommendations.

Figure 2 displays the number of added-to-buy recommendations by analysts (light grey bars) and journalists (dark grey bars) by year.

We can see that during the years when the stock market reached its highpoint, i.e. 1999 and 2000, journalists acted as the cheerleader for buying stocks by increasing the number of new buy recommendations. While journalists doubled the number of initiated and changed recommendations from 1998 to 2000, the number of analyst recommendations remained about unchanged.

Figure 3 shows the distribution of recommendations over calendar months of publication. 
Figure 2: Added-to-buy recommendations per year. Light grey bars indicate added-to-buy recommendations from analysts, and dark grey bars indicate added-to-buy recommendations from journalists.

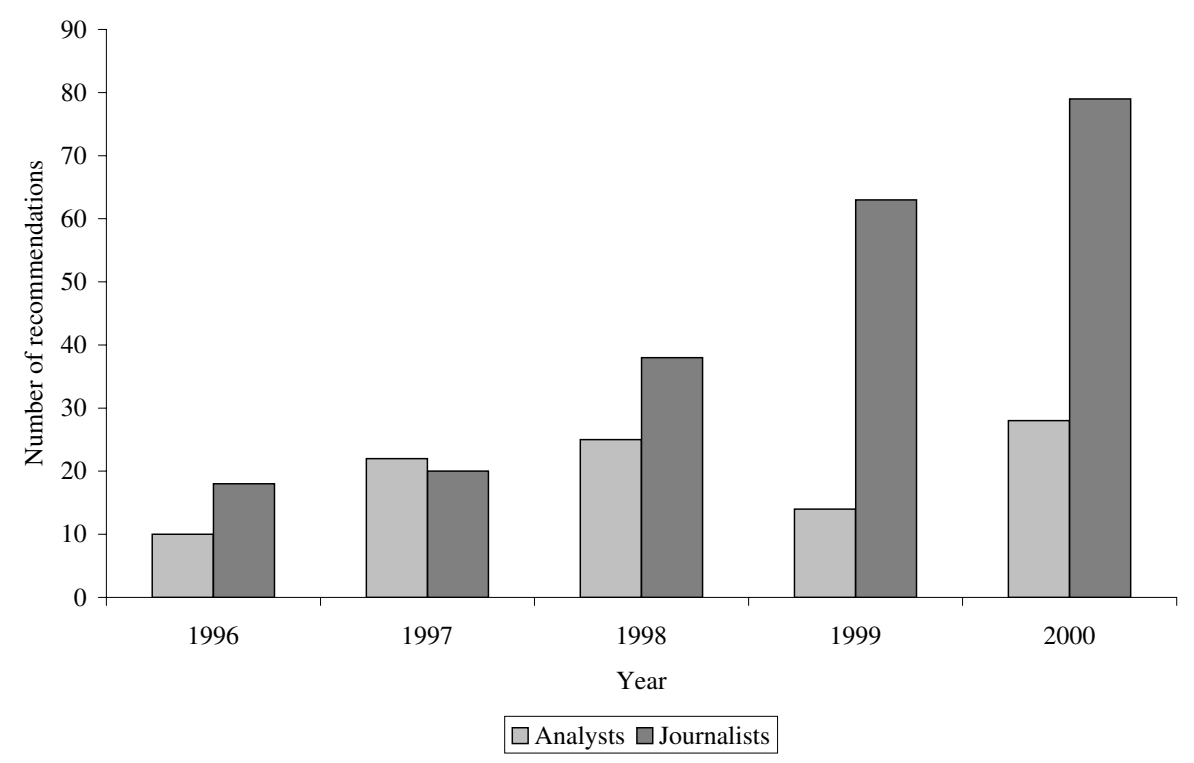

Figure 3: Recommendations per calendar month. Grey bars indicate addedto-buy recommendations and the black bars added-to-sell recommendations published per calendar month. The line indicates their ratio.

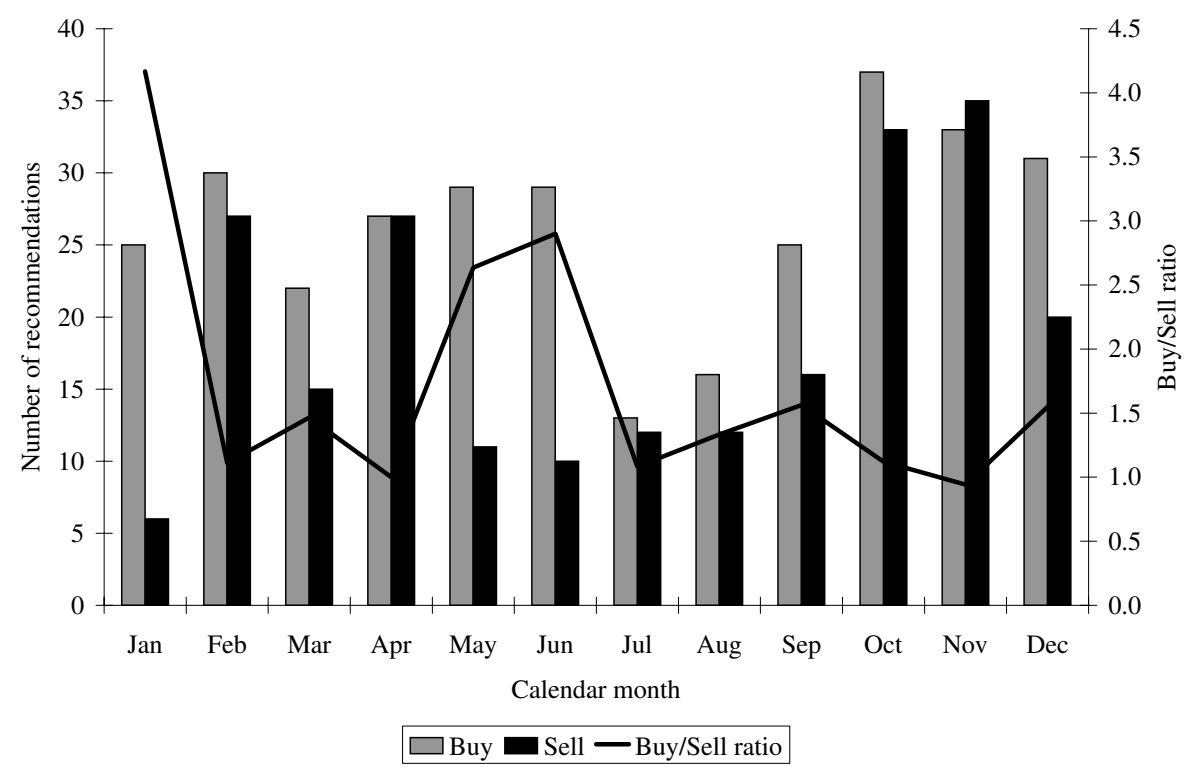


Added-to-buy recommendations were fairly evenly distributed over calendar months with no clear higpoint, whereas added-to-sell recommendations were somewhat "clustered" during October-November. The buy-to-sell ratio reached 4:1 during January, which was the highpoint, and in June it was $3: 1$. The ratio in January comes as no surprise since printed media publishes recommendations of stocks to buy during the new year. The peak in June, however, is a surprise. In fact, we could have expected relatively more sell recommendations for people who needed money for their holidays. The ratio reached its lowpoint in November, with many recommendations to sell for tax reasons.

The daily stock prices come from the Scandinavian Information Exchange (SIX) and were adjusted for dividends being reinvested in the stock from the ex-dividend day.

\section{Method and Hypotheses}

Previous research on long-term performance after various corporate events has evaluated abnormal performance based either on the buy-and-hold abnormal return method (BHAR), or the cumulative abnormal return method (CAR). A reason for the widespread use of BHAR is that it more accurately captures investor experience from holding a security for a long postpublication period; hence it is more intuitive than other methods. However, some have argued that this method does not correct for the cross-sectional dependence of observations due primarily to overlapping returns. ${ }^{10}$ Because we here allow only initiations and changes from previous recommendations, the amount of overlapping returns, and thereby its potential problem, can be kept at an absolute minimum. In Barber and Lyon (1997) it was also discussed that, even though BHARs give rise to negatively biased test statistics, it is nevertheless preferred for detecting overperformance of published recommendations.

\subsection{Buy-and-hold Abnormal Return (BHAR)}

Each recommendation was assigned $t=0$ for the publication-day (PD), and the event-period (EP) consists of the days -1 to +1 . Data was required to be available one month before the start of the EP (21 trading days) and up to 24 months after the PD. Because it is almost impossible for an investor to profit from information contained in an announcement released before the

\footnotetext{
${ }^{10}$ Criticism towards BHAR for this reason have been raised by Brav and Gompers (1997), Fama (1998), Barber et al. (1999), and Mitchell and Stafford (2000).
} 
opening, we assume an investor to invest at the day after the PD for our post-recommendation performance calculations. ${ }^{11}$ To minimize the effect of survivorship bias when a firm did not survive the 24 months, abnormal performance was estimated for as many months as data were available, a procedure also used in Kothari and Warner (1997).

Calculating the BHARs for each recommended stock $i$ during the period $T$, we use the procedure

$$
B H A R_{i T}=\prod_{t=1}^{T}\left[1+R_{i T}\right]-\prod_{t=1}^{T}\left[1+R_{I T}\right],
$$

where the period $T$ will be calculated for the month prior to the EP (from day -22 to day -2), during the EP, as well as for 6, 12, 18, and 24 post-event months; and $I$ is the return on a value-weighted industry index to which stock $i$ belongs. By industry index we mean sector index as classified by the Global Industry Classification System (GICS) jointly created by Morgan Stanley Capital International and Standard 8 Poors. Mean BHARs for a certain type of recommendations and from a certain group were calculated as a simple mean, i.e. each stock in that portfolio is equally weighted. This way of calculating the mean BHAR is preferred since it, in practice, means than an investor mimicking the recommendations would invest an equal amount of money in each recommended stock.

\subsection{Hypotheses}

If we assume that markets are at least semi-strong efficient, investing according to publicly available stock recommendations should not yield abnormal long-run returns. Markets tend to react rapidly to new information. They react so fast to this information that it would be almost impossible for a professional investor with all available tools to profit from it. Indeed, Kim et al. (1997) have shown that it only takes about 5 and 15 minutes for stock prices at NYSE and NASDAQ to react to the private information in analyst recommendations. This leads us to our first hypothesis:

Hypothesis 1: The main body of previous research have found stock recommendations in printed media to be of practically no additional value, therefore we should not expect the Swedish printed media to be any different.

Analysts, and the bank or brokerage firm he or she represents, spends huge

\footnotetext{
${ }^{11}$ That it is close to impossible to profit from this information have been showed in Kim et al. (1997).
} 
resources in order to pick a few investment opportunities. In order to compensate their commission-paying clients and themselves for this research-cost, these investment advice should, on average, be outperforming the appropriate comparison measure. Prior to being published in the respective newspaper or business magazine, this information have thus already been passed on to private clients. So, if this information was somehow first-hand initially, i.e. profitable, it should not be profitable by the time they are published. These recommendations are then second-hand at the $\mathrm{PD}$, just as journalist recommendations are assumed to be. As such, they should perform in line with the market, at best. Our second expectation can therefore be stated as:

Hypothesis 2: There should be no difference between the long run performance of analyst and journalist recommendations.

\section{Empirical Results}

The buy-and-hold abnormal returns for all buy- and sell recommendations are presented in Table 3.

Buy recommendations were of stocks that performed as the market in the month prior to the recommendation (Panel A). During the EP these stocks gave rise to an abnormal return of $2.31 \%$ (with a $t$-value of 3.48 ), but during the post-publication periods, these recommendations yielded negative BHARs. For the 18 months following the publication day, they would actually have yielded a return of $-10.32 \%$ (with a $t$-value of -1.67 ) for an investor acting on them after accounting for the return in the industry of the particular stock. $^{12}$

In the literature, smaller companies are said to react more heavily to company-related announcements than larger companies. ${ }^{13}$ It is therefore important to control for market capitalization when talking about BHARs. It could also be that the BHARs are driven by earnings-announcements just before, at, or after the recommendation is published. Therefore, we also run the following regression:

\footnotetext{
${ }^{12}$ We also run a regression having the 18-month BHAR as the dependent variable, and as dependent variables a dummy controlling from whom the recommendation originated, a variable controlling for market capitalization differences, a dummy controlling for whether the recommendation was published during the year 2000, and dummies controlling for in what newspaper or business magazine it was published. The result from this regression shows that the constant is no longer statistically significant, hence we cannot say that it would have been a profitable investment strategy to short these stocks.

${ }^{13}$ The well-known size-effect in this setting is discussed in Dimson and Marsh (1986).
} 
Table 3: BHARs for buy- and sell recommendations. The pre-event period consists of the month prior to the event period (from day -22 to -2). In Panels A-C, the BHARcolumns displays the BHAR for buy recommendations, sell recommendations, and the combined effect from the two (where the return from sell recommendations have been assigned a negative sign). In Panel $\mathrm{D}$, the first BHAR-column measures the difference between the first BHAR-columns of Panel $\mathrm{C}$ and $\mathrm{B}$, the second BHAR-column displays the difference between the second BHAR-columns of Panel C and B, etc, performing a Wilcoxon ranksum test. $*=$ significant at the 10 -percent level, $* *=$ significant at the 5 -percent level, and ${ }^{* * *}=$ significant at the 1 -percent level using a two-tailed $t$-test.

\section{Panel A: All recommendations}

Buy recommendations

\begin{tabular}{lccrrrrrrr} 
Period & BHAR & $t$ & $\mathrm{n}$ & BHAR & $t$ & $\mathrm{n}$ & BHAR & $t$ & $\mathrm{n}$ \\
\hline Pre-publication & 0.16 & 0.13 & 317 & 1.29 & 0.70 & 224 & - & - & - \\
Event-period & 2.31 & $3.48^{* * *}$ & 317 & -1.36 & $-3.30^{* * *}$ & 224 & - & - & - \\
6 months & -2.59 & -1.10 & 317 & -4.96 & $-1.89^{*}$ & 224 & 0.54 & 0.30 & 541 \\
12 months & -2.63 & -0.76 & 315 & -10.62 & $-2.70^{* * *}$ & 223 & 2.85 & 1.09 & 538 \\
18 months & -10.32 & $-1.67^{*}$ & 308 & -11.42 & $-2.58^{* *}$ & 213 & -1.41 & -0.34 & 521 \\
24 months & -6.57 & -1.32 & 296 & -15.88 & $-3.51^{* * *}$ & 208 & 2.70 & 0.77 & 504
\end{tabular}

Panel B: Analyst recommendations

\begin{tabular}{lccccccccc} 
Period & BHAR & $t$ & $\mathrm{n}$ & BHAR & $t$ & $\mathrm{n}$ & BHAR & $t$ & $\mathrm{n}$ \\
\hline Pre-publication & -3.68 & $-2.51^{* *}$ & 99 & -3.25 & -1.60 & 35 & - & - & - \\
Event-period & 1.15 & $1.94^{*}$ & 99 & 0.21 & 0.31 & 35 & - & - & - \\
6 months & 2.07 & 0.41 & 99 & -7.94 & $-2.06^{* *}$ & 35 & 3.60 & 0.92 & 134 \\
12 months & -0.96 & -0.16 & 99 & -14.76 & $-2.19^{* *}$ & 35 & 3.14 & 0.65 & 134 \\
18 months & -4.00 & -0.57 & 95 & -30.58 & $-2.87^{* * *}$ & 34 & 5.11 & 0.85 & 129 \\
24 months & -7.77 & -0.90 & 94 & -35.73 & $-3.25^{* * *}$ & 33 & 3.53 & 0.49 & 127
\end{tabular}

Panel C: Journalist recommendations

\begin{tabular}{lrrrrrrrrr} 
Period & BHAR & $t$ & $\mathrm{n}$ & BHAR & $t$ & $\mathrm{n}$ & BHAR & $t$ & $\mathrm{n}$ \\
\hline Pre-publication & 1.91 & 1.11 & 218 & 2.13 & 1.00 & 189 & - & - & - \\
Event-period & 2.84 & $3.06^{* * *}$ & 218 & -1.65 & $-3.51^{* * *}$ & 189 & - & - & - \\
6 months & -4.71 & $-1.87^{*}$ & 218 & -4.41 & -1.45 & 189 & -0.47 & -0.24 & 407 \\
12 months & -3.39 & -0.80 & 217 & -9.85 & $-2.19^{* *}$ & 188 & 2.76 & 0.89 & 405 \\
18 months & -13.14 & -1.57 & 213 & -7.80 & -1.62 & 180 & -3.55 & -0.70 & 393 \\
24 months & -6.01 & -0.99 & 203 & -12.15 & $-2.47^{* *}$ & 176 & 2.42 & 0.61 & 379
\end{tabular}

Panel D: Analysts versus journalists

\begin{tabular}{lcrrcrc} 
Period & BHAR & \multicolumn{1}{c}{$z$} & BHAR & $z$ & BHAR & $z$ \\
\hline Pre-publication & -5.59 & -0.92 & -5.38 & -0.57 & - & - \\
Event-period & -1.69 & -1.00 & 1.86 & $1.86^{*}$ & - & - \\
6 months & 6.78 & 0.52 & -3.53 & -0.63 & 4.07 & 0.16 \\
12 months & 2.43 & 0.40 & -4.91 & -0.25 & 0.38 & -0.22 \\
18 months & 9.19 & 0.04 & -22.78 & -1.57 & 8.66 & 1.10 \\
24 months & -1.76 & -1.08 & -23.53 & $-1.67^{*}$ & 1.11 & -0.85 \\
& & & & & & \\
\hline \hline
\end{tabular}




$$
\begin{aligned}
\operatorname{BHAR}_{(E P, i)}^{\text {Buy }}= & 18.59-0.74 \text { Size }_{i}-1.95 \text { Earn }_{i} \\
& \left(1.89^{*}\right)\left(-1.76^{*}\right) \quad(-0.55) \\
& \bar{R}^{2}=0.02
\end{aligned}
$$

where $B H A R_{(E P, i)}^{B u y}$ measures the BHAR for buy recommendations during the period starting from the day prior to the $\mathrm{PD}$ and ending on the day after the PD for each stock $i$; Size $e_{i}$ is the log of market capitalization; and Earn $_{i}$ is a dummy which takes the value of one if the company being buy-recommended issued an earnings-announcement during the EP and zero otherwise. Standard errors are corrected for heteroscedasticity using the procedure in White (1980). T-statistics are reported in parentheses.

The regression result in equation 2 shows that, even though market capitalization differences comes out statistically significant, the constant does as well. This means that buy recommendations give rise to a positive pricereaction during the EP. The fact that nine companies issued earnings announcements during the EP does not seem to be an important factor explaining the BHAR during this period. The companies issuing earningsannouncements nevertheless decreased by almost two percent during this period.

Sell recommendations were also of stocks that had a price increase during the month prior to the recommendation. During the EP, these stocks decreased in price. For the coming two years they yield statistically significant negative BHARs, e.g. $-15.88 \%$ (with a $t$-value of -3.51 ). This means that it would be a profitable investment strategy to short the sell-recommended stocks.

As was previously done with buy recommendations, we ensure that the reaction to the sell recommendations was not due to differences in market capitalization, and whether the company issued an earnings announcement during the event period by running the following regression:

$$
\begin{aligned}
\operatorname{BHAR}_{(E P, i)}^{\text {Sell }}= & -14.96+0.61 \text { Size }_{i}-1.40 \text { Earn }_{i} \\
& \left(-3.27^{* * *}\right)\left(3.13^{* * *}\right) \quad(-0.41) \\
& \bar{R}^{2}=0.04
\end{aligned}
$$

where $B H A R_{(E P, i)}^{S e l l}$ measures the BHAR for sell recommendations during the EP for each stock $i$; the other variables are as before. Standard errors are corrected for heteroscedasticity using the procedure in White (1980). Tstatistics are reported in parentheses. As was the case for buy recommendations, the stock market seems to react to published sell recommendations 
since prices decreases, i.e. there is some information in the recommendations making the market "adjusting" prices. The BHAR during the EP can partly be explained by differences in market capitalization, i.e. smaller stocks have a larger price-reaction than larger stocks have. Again, the six occasions of documented earnings announcements during the EP does not seem to be an important factor in explaining the EP-BHAR.

We also run a regression where BHAR for the 24-month post-publication period is the dependent variable, and as independent variables: a variable controlling for market capitalization; also ,in order to control for recommendations given during year 2000 being different in BHARs from the 19961999-period, a dummy controlling for whether the recommendation was given during the year of 2000 or not was introduced; and dummies controlling for in which newspaper or business magazine it was published:

$$
\begin{aligned}
\text { BHAR }_{(24 \text { post-months }, i)}^{\text {Sell }}= & -209.82+8.95 \text { Size }_{i}+15.78 y 2000_{i} \\
& \left(-4.51^{* * *}\right)\left(4.90^{* * *}\right) \quad\left(2.00^{* *}\right) \\
& + \text { newspaper dummies } \\
& \bar{R}^{2}=0.11 .
\end{aligned}
$$

Standard errors are corrected for heteroscedasticity using the procedure in White (1980). T-statistics are reported in parentheses. The multivariate regression in equation 4 shows that increasing market capitalization of the recommended stock as well as if the recommendation was published during the year 2000 influenced the 24-month post-publication BHAR "positively". This means that sell recommendations during 2000 that were of relatively large companies generally performed worse than did other recommendations. That these recommendations performed worse means that the stock price of the respective company did not decrease as much as did the relatively smaller companies sell-recommended during the 1996-1999 period. The statistically significant constant should be interpreted as it would be a profitable investment strategy to short the sell-recommended stocks. ${ }^{14}$

Combining the impact from buy- and sell recommendations, we can see that they would have left an investor following them with a return of 2.70 $\%$ (with a $t$-value of 0.77 ) more than there industry peers for the 24 -month period. So, the initiated or changed stock recommendations published in Swedish printed media performed in line with their industry peers. In subsection 3.1 it was stated that we should not expect the sample recommendations to outperform the market (Hypothesis 1). Although sell recommendations

\footnotetext{
${ }^{14}$ It should be stressed, however, that shorting stocks may not always be possible.
} 
on its own may be profitable to follow, taking the negative contribution from buy recommendations into account, these recommendations perform in line with the market. The results therefore support the hypothesis.

The fact that buy-recommended stocks decrease in price during the 24 post-publication months, while sell-recommended stocks increase, makes us believe that shorting stocks receiving any recommendation could be profitable. If the investor would have adopted this strategy for the period of interest, he/she would have gained some $10.42 \%$ (with a $t$-value of 3.00).

The above results have shown that buy recommendations were misleading investors, while sell recommendations were leading them. Sell recommendations were thus informative but buy recommendations were not. The management in the company are usually overoptimistic about the future prospects of the company. Naturally, this means that the estimations presented by the management will be positively biased. When there is positive information, management tend to be excessively upbeat about the future. This sometimes leads to buy recommendations from analysts and journalists. The market reacts to the information in the recommendations leading to increasing stock prices, but after the PD, stock prices falls back. This is a classical overreaction. The reaction, however, takes considerable time, i.e. the market does not initially recognize the full extent of the positive bias. On the other hand, when management releases negative information, this is again presented as being slightly better than it actually is. This sometimes leads to sell recommendations from analysts and journalists. Again, the market reacts to the information with decreasing stock prices as a result. This time stock prices also decreases after the PD, i.e. the market underreacts. As for buy recommendations, it takes a considerable amount of time for the market to understand the positive bias in management information.

One may say that there is an informational-asymmetry dilemma between management on the one hand, and analysts and journalists on the other. If we analyze the results presented in this section, it is obvious that analysts and journalists were fooled by the overoptimism from the positive information, but they were not from negative information. In turn, this is due to positive information being more intricate to interpret.

\subsection{Analysts versus Journalists}

Table 3 also shows BHARs divided into recommendations from analysts (Panel B) and journalists (Panel C), as well as a comparison between the two groups (Panel D).

Buy-recommended stocks from analysts performed worse than those from journalists during the pre-publication month. During the EP, the stock- 
price reaction to these recommendations were much lower than it was to buy recommendations from journalists. The market consequently believes that journalist buy recommendations contain relatively more new information. During the following months, however, these recommendations performed marginally better than journalist recommendations (as displayed by the 6-, 12-, and 18-month BHARs in the first BHAR-column of Panel D).

The pre-publication month BHAR to sell-recommended stocks from analysts was about 5 percent lower than it was for journalist sell recommendations. The EP BHAR to the sell-recommended stocks by analysts was higher than it was to sell-recommended stocks from journalists, i.e. sell recommendations from journalists were valued higher by the market during this period (just as for buy's). During the post-publication periods, however, these recommendations gave rise to continuous decreases in stock prices, leading to sell recommendations from analysts outperforming those from journalists. Sell recommendations from analysts "outperformed" sell recommendations by journalists with $23.53 \%$ (with a $z$-value of -1.67 ) for the 24 -month postpublication period. ${ }^{15}$

We also run a regression where we let the 24-month BHAR to sell recommendations be the dependent variable, and in addition to the independent variables in equation 4 , we also include the dummy $W h o_{i}$ which takes one if an analyst gives the recommendation and a zero if it is a journalist. Standard errors are corrected for heteroscedasticity using the procedure in White (1980). T-statistics are reported in parentheses.

$$
\begin{aligned}
\operatorname{BHAR}_{(24 \text { post-months }, i)}^{\text {Sell }}= & -194.95-18.31 W^{\text {Who }} \text { + }+8.65 \text { Size }_{i} \\
& \left(-4.25^{* * *}\right)(-1.56) \quad\left(4.74^{* * *}\right) \\
& +12.85 y 2000+\text { newspaper dummies } \\
& (1.52) \\
& \bar{R}^{2}=0.11 .
\end{aligned}
$$

The results in equation 5 clearly show that when we take into account differences in size between recommendations, as well as year of recommendation and in which newspaper the recommendation was given, the $W h o_{i}$-variable does not come out as a statistically significant factor in explaining the 24month BHAR for sell recommendations. This means that we cannot say that sell recommendations from analysts outperforms sell recommendations from journalists.

\footnotetext{
${ }^{15} \mathrm{~A}$ word of caution should be raised by the limited sample of sell recommendations from analysts, i.e. only 35 sell recommendations.
} 
The last column of Table 3 in Panel D compares the last two columns of Panel B and C. From rows 3 to 6 of that column, we can see that an investor who follow analyst initiated or changed recommendations would earn just marginally more than the comparative investor following journalist recommendations although not statistically different from zero. The overall picture of the results tells us that analyst and journalist recommendations yields returns in line with the market. This finding supports our previously stated hypothesis (Hypothesis 2) that recommendations from analysts and journalists should be performing equally as well.

Buy recommendations were earlier found to be misleading and sell recommendations to be leading investors. Dividing the sample into recommendations from analysts and journalists, these results still holds. That is, buy recommendations from both analysts and journalists were misleading, whereas sell recommendations from them were leading.

\subsection{Transaction Costs}

So far we have totally ignored costs imposed from transacting. In reality this can not be foreseen and should always be included when we evaluate the profitability from mimicking a set of recommendations. Nowadays, costs from transacting in stocks approaches levels close to negligible. Since the results are calculated such that the investor mimicking these recommendations would buy (or sell) the stock and hold on to them for a certain period of time, and then sell (or buy back) the stock, this gives rise to a two-trip transaction cost. Assuming that the investor is based in Sweden, online brokerage firms charge a fee of around $0.10 \%$ on the value of the transaction each way. Obviously, including for transaction costs, the results would not change dramatically, i.e. only about $0.20 \%$.

\section{$5 \quad$ Summary and Conclusions}

This paper analyzes the long-run returns from mimicking initiated or changed stock recommendations given by analysts and journalists and published in Swedish printed media. The sample period is 1996-2000, which covers the turbulent 1999-2000 period. If an investor followed all initiations and changes, he or she would not earn more than the market return. This result is in line with our beliefs prior to performing this study, as well as the major body of previous research in the field. Following only sell recommendations, however, an investor could earn substantial buy-and-hold abnormal returns. This holds for sell recommendations from both analysts and journalists. One 
should of course keep in mind that following such recommendations means taking short positions which may or may not be possible in the recommended stock at that point in time, i.e. there may be a liquidity problem involved in such a transaction. This liquidity problem may lead to a shrinking possibility to profit from that information. Following all recommendations from either analysts or journalists yields returns in line with industry peers, and no sizeable difference between the two groups was observed. Our expectations that analysts would hand their information to private clients to profit from before publication, leading to analyst and journalist recommendations performing equally as well in the post-recommendation periods, is therefore supported. Since all recommendations perform in line with their industry peers, an investor would be equally well off holding the market index.

Apart from the profitable trading strategy to short stocks that receives a sell recommendations, there is yet another feasible and potentially profitable trading strategy. This strategy involves shorting all buy- and sellrecommended stocks, i.e. going against buy recommendations but in line with sell's. This strategy would have yielded a statistically significant BHAR of about 10 percent, assuming that shorting these stocks is possible at the time of the recommendation.

The results of this paper have shown stock recommendations in Swedish printed media during the period to be both misleading (regarding buy recommendations) and leading (regarding sell recommendations). We have also shown that this asymmetry exists for recommendations originating both from analysts and journalists. As we have mentioned earlier in the paper, this could possibly be due to winners being more difficult to pick than losers. The explanation behind the asymmetry is that company management are generally overoptimistic about the future prospects of its company. This overoptimism generates positively biased information from the management to the public, in good times and bad. Because of the complexity in understanding the future prospects of the company, the overoptimism in positive information from management deceives analysts and journalists to issue misleading buy recommendations.

Another detail that previous research have seemed to ignore, is the existing conflicts-of-interest issues when analysts give recommendations in printed media. The ties between the analyst employer and the recommended company was consistently foreseen in the sample recommendations. Ongoing corporate finance activities must be fully disclosed in connection to a recommendation. How can we otherwise expect investors, i.e. readers of the newspapers and business magazines, to make good and healthy investments based on these investment advice? 


\section{References}

Barber, B. M., R. Lehavy, M. McNichols, and B. Truemann (2001). Can investors profit from the prophets? Journal of Finance 56(2), 531-563.

Barber, B. M. and J. D. Lyon (1997). Detecting long-run abnormal stock returns: The empirical power and specification of test statistics. Journal of Financial Economics 43, 341-372.

Barber, B. M., J. D. Lyon, and C.-L. Tsai (1999). Improved methods for tests of long-run abnormal stock returns. Journal of Finance 54(1), 165-201.

Bertaut, C. C. and W. L. Griever (2004). Recent Developments in CrossBorder Investment in Securities. Federal Reserve Bulletin Winter, 19-31.

Bjerring, J. H., J. Lakonishok, and T. Vermaelen (1983). Stock Prices and Financial Analysts' Recommendations. Journal of Finance 38(1), 187204.

Brav, A. and P. A. Gompers (1997). Myth or reality: The long-run underperformance of initial public offerings. Journal of Finance 52, 1791-1821.

Desai, H., B. Liang, and A. K. Singh (2000). Do All-Stars Shine? Evaluation of Analyst Recommendations. Financial Analysts Journal May/June, 2229.

Dimson, E. and P. Marsh (1986). Event Study Methodologies and the Size Effect. Journal of Financial Economics 17, 113-142.

Fama, E. F. (1998). Market efficiency, long-term returns, and behavioral finance. Journal of Financial Economics 49, 283-306.

Ferreira, E. J. and S. D. Smith (2003). Wall \$treet Week: Information or Entertainment? Financial Analysts Journal January/February, 45-53.

Karmin, C. (2000). Investors Jump on the Nordic Track in Search Of Hot Telecommunications and Internet Shares. Wall Street Journal 59(235), C20.

Kim, S. T., J.-C. Lin, and M. B. Slovin (1997). Market Structure, Informed Trading, and Analysts' Recommendations. Journal of Financial and Quantitative Analysis 32(4), 507-524.

Kothari, S. P. and J. B. Warner (1997). Measuring long-horizon security price performance. Journal of Financial Economics 43, 301-339. 
Liang, B. (1999). Price Pressure: Evidence from the "Dartboard" Column. Journal of Business 72(1), 119-134.

Lidén, E. R. (2003). Swedish Stock Recommendations: Information Content or Price Pressure? Working Paper in Economics No. 98, Department of Economics, School of Economics and Commercial Law, Göteborg University.

Mathur, I. and A. Waheed (1995). Stock Price Reactions to Securities Recommended in Business Week's "Inside Wall Street". Financial Review 30, 583-604.

Mitchell, M. L. and E. Stafford (2000). Managerial Decisions and Long-Term Stock Price Performance. Journal of Business 73(3), 287-329.

Muradoğlu, G. and B. Yazici (2002). Dissemination of Stock Recommendations and Small Investors: Who Benefits? Multinational Finance Journal $6(1), 29-42$.

White, H. (1980). A Heteroscedasticity Consistent Covariance Matrix Estimator and a Direct Test of Heteroscedasticity. Econometrica 48, 817-838.

Womack, K. L. (1996). Do Brokerage Analysts' Recommendations Have Investment Value? Journal of Finance 51(1), 137-167. 


\section{Appendix}

\section{A Circulation estimates}

Circulation estimates for the sample newspapers and business magazines as of 31 December 2000. * Average over weekend days ** Sunday figures. Source: TS AB.

\begin{tabular}{cc}
\hline \hline & \\
Newspaper & Circulation \\
& \\
\hline AFV & 27,600 \\
AB & $117,000^{*}$ \\
FTi & 38,300 \\
GP & $380,600^{* *}$ \\
PA & 27,400 \\
VA & 288,500 \\
& \\
\hline \hline
\end{tabular}




\section{B Stockholm Stock Exchange ownership}

The black line indicates Swedish ownership excluding the households, the grey line indicates the Swedish households ownership, and the dashed black line foreign ownership. All figures are in percentage of total market share. Source: Statistics Sweden (SCB).

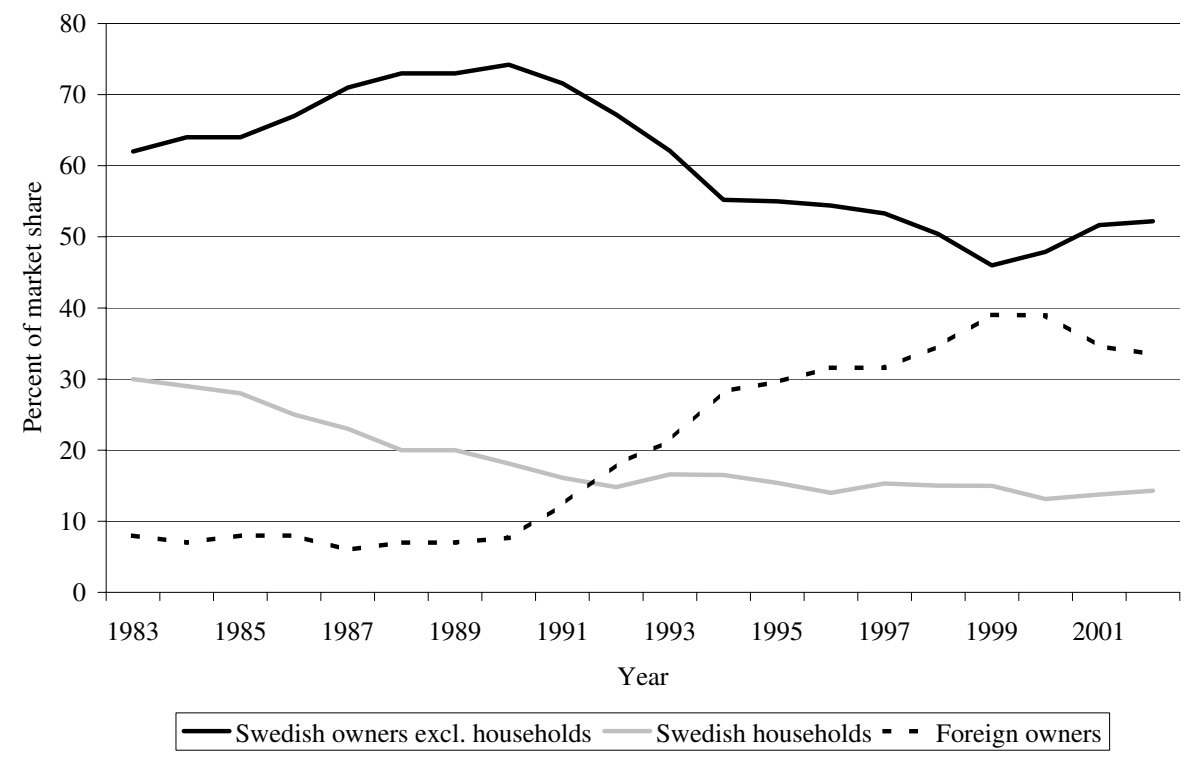

